\title{
Review Article \\ Dual Role of Nano Ceria- as an Antioxidant and as a Prooxidant
}

T Dharshni ${ }^{1 *}, \mathrm{~V}$ Thendral ${ }^{1 * *}, \mathrm{R}$ Murugesan ${ }^{* * *}$, Agnishwar Girigoswami $^{* * * *}$, Koyeli Girigoswami ${ }^{* * * * *}$

${ }^{*}$ Postgraduate, Madras University, ${ }^{* *}$ Postgraduate, Bharathiar University, ${ }^{* * *}$ Director Research, ${ }^{* * * *}$ Professor,

${ }^{* * * * *}$ Associate Professor, Medical Bionanotechnology, Faculty of Allied Health Sciences, Chettinad Hospital and Research Institute, Chettinad Academy of Research and Education, Chettinad Health City, Kelambakkam, Chennai, Tamilnadu, India

${ }^{1}$ Both authors have contributed equally to this article

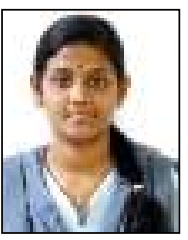

T. Dharshni has completed B.Sc. in Medical Bionanotechnology in 2017 from Chettinad Academy of Research and Education, Kelambakkam, Chennai. She has done her undergraduate project under the guidance of Dr. Koyeli Girigoswami, Associate Professor, FAHS, CHRI, CARE. She pursued her M.Sc. in Nanoscience and Nanotechnology from Madras University, Chennai in 2019. Her research interest includes metal and metal oxide nanoparticles and its biomedical applications

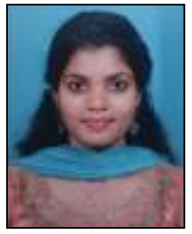

V. Thendral has completed B.Sc. in Medical Bionanotechnology in 2017 from Chettinad Academy of Research and Education, Kelambakkam, Chennai. She has done her undergraduate project under the guidance of Dr. Koyeli Girigoswami, Associate Professor, FAHS, CHRI, CARE. She pursued her M.Sc. in Nanoscience and Technology from Bharathiar University, Coimbatore in 2019. Later, she worked in a DST Project in Jain University, Bangalore. Currently, she is pursuing her PhD in Madras University, Chennai. Her research interest includes microfluidics, metal and metal oxide nanoparticles.

Corresponding author - Dr. Koyeli Girigoswami (koyelig@gmail.com)

Chettinad Health City Medical Journal 2020; 9(1): 59 - 65

DOI: https://doi.org/10.36503/chcmj9(1)-11

\begin{abstract}
Metal oxide nanoparticles are profoundly used in different fields of biological applications as well as in physics due to their unique characteristics of semiconducting nature at nano size. The surface to volume ratio increases enormously thereby making these metal oxide nanoparticles physicochemically different from their bulk counterpart. In this book chapter we will discuss about cerium oxide nanoparticles (CeO-NPs) and its different valance states which enables it to act both as a prooxidant as well as an antioxidant. CeO-NPs are used in different products like catalyst in solar cells, sensors and catalyst for detection of certain gases, as antioxidant, in biomedical field etc. Due to its profound applications the toxicity exerted by these CeO-NPs needs to be explored. There are conflicting evidences regarding the toxicity of CeO-NPs as found from previous literatures. In some cases, it is known as a reactive oxygen species (ROS) scavenger whereas in some it is known to exert oxidative stress. This dual nature is attributed to the coexistence of its two valance states $\mathrm{Ce}^{+3}$ and $\mathrm{Ce}^{+4}$. Thus, the transition between these two states play an important role in deciding whether CeO-NPs is an oxidant or an antioxidant and how it mimics the different antioxidant enzymes like superoxide dismutase (SOD) and catalase (CAT). These topics will be discussed elaborately in this review.
\end{abstract}

Key words : nanoceria, antioxidant properties, nanoceria as prooxidant, ROS scavenging, cerium oxide stoichiometry

\section{Introduction}

In many fields of chemistry, physics and materials science, metal oxides are widely used. ${ }^{1-6}$ Metal oxide nanoparticles can be found in several geometrical structures such as tubes, spheres, prisms, flowers and rods having electronic structure that enables them to have metallic, semiconductor or insulating character. The band gap of the nanoparticles enables them to possess a semiconducting nature. Cerium oxide nanoparticles (CeO-NPs) are one of the metal oxide nanoparticles which have excellent catalytic activities that are derived from $\mathrm{Ce}^{4+}$ and
$\mathrm{Ce}^{3+}$ oxidation state. The electronic configuration of cerium atom has the ability to easily and drastically adjust to its environment. It arises through loss of oxygen and/or its electrons, alternating between $\mathrm{CeO}_{2}$ and $\mathrm{CeO}_{2-x}$ during redox reactions and also exhibits oxygen vacancies, or defects, in the lattice structure. CeO-NPs are recently found to mimic the multi-enzyme activities like superoxide dismutase (SOD) and catalase (CAT). In biological fields such as biology, medicine, bioanalysis, biomedicine, drug delivery, and bioscaffolding, $\mathrm{CeO}-\mathrm{NPs}$ has emerged as an effective nanomaterial.7, 8 The existence of 
cerium is as a rare earth metal of the Lanthanide series which has an atomic number of $5 .^{8}$ It is well known that the metals in rare earth series exist mostly in trivalent state, however cerium is an exception. The electronic configuration of cerium $\left([\mathrm{Xe}]_{4} \mathrm{f}_{5}{ }_{5} \mathrm{~d}_{6} \mathrm{~S}^{2}\right)$ can display both the trivalent $(+3)$ $\left(\mathrm{Ce}^{3+}=[\mathrm{Xe}]_{4} \mathrm{f}_{1}\right)$ and tetravalent $(+4)\left(\mathrm{Ce}^{4+}=[\mathrm{Xe}]\right)$ oxidation states. ${ }^{9,10}$ Due to the antiemetic, bacteriostatic, bactericidal, immunomodulating and antitumor activity, $\mathrm{Ce}^{3+}$ salts (nitrate, acetate, chloride, etc.) have been traditionally used by humans for biomedical purposes. ${ }^{11,} 12$ The capacity to actively scavenge a variety of both reactive oxygen species (ROS) and reactive nitrogen species (RNS) in cell and animal models demonstrated antioxidant enzyme-mimetic activity of CeO-NPs. In current scenario, as catalysts and as structural and electronic promoters of heterogeneous catalytic reactions, CeO-NP and CeO-NP-containing materials have come under intense scrutiny. ${ }^{13}$ Since, the $\mathrm{Ce}$ atom exists in both trivalent $\left(\mathrm{Ce}^{3+}\right)$ and more stable tetravalent $\left(\mathrm{Ce}^{4+}\right)$ state, it allows the nanoparticles to store and release oxygen when present in the form of $\mathrm{CeO}_{2}{ }^{14} \mathrm{To}$ increase its catalytic properties in industry, it is desirable to produce $\mathrm{CeO}_{2}$ with increased oxygen storage and releasing properties.

\section{Stoichiometric state of $\mathrm{Ce}^{3+}$ and $\mathrm{Ce}^{4+}$}

To a certain extent, both the enzyme-mimetic and ROS/RNS scavenging capacity of CeO-NPs is dependent on the physicochemical properties of the nanoscale materials and the thermodynamic efficiency of redox cycling between $\mathrm{Ce}^{3+}$ and $\mathrm{Ce}^{4+}$ ions on the surface of CeO-NPs. ${ }^{10,} 15$ Cerium oxide can exist as pure $\mathrm{CeO}_{2}\left(\mathrm{Ce}^{4+}\right)$ or $\mathrm{Ce}_{2} \mathrm{O}_{3}\left(\mathrm{Ce}^{3+}\right)$ in bulk scale and compared to bulk scale, the surface of CeO-NP contains a mixture of both $\mathrm{Ce}^{4+}$ and $\mathrm{Ce}^{3+}{ }^{36}, 17$ The absolute diameter of the CeO-NP decreases (e.g., from $20 \mathrm{~nm}$ to $2 \mathrm{~nm}$ ) when there is a loss of oxygen atom and there is an increase in the $\mathrm{Ce} 3+$ ions on the surface of the nanoparticles. ${ }^{18-20}$ When $\mathrm{Ce}^{4+}$ is converted to $\mathrm{Ce}^{3+}$ thereby changing the oxidation state of $\mathrm{Ce}$, the number of vacancies for oxygen are increased on the surface of CeO-NP, as oxygen is lost from the surface. The antioxidant/ enzyme-mimetic activity of the CeO-NPs is directly proportional to the ratio of $\mathrm{Ce}^{3+} / \mathrm{Ce}^{4+}$ sites available on the surface of the nanoparticle. Each oxygen vacancy is created by the reduction of two surface $\mathrm{Ce}^{4+}$ ions to maintain the stability of electronic charge. Thus, the oxygen vacancy present under these conditions can be illustrated using the formula $\mathrm{CeO}_{2-x}$ showing the structural stability of CeO-NPs. ${ }^{18}$ Studies have found a dual nature of CeO-NPs either it exhibits toxicity mediated by production of $\operatorname{ROS}^{21,22}$ or by acting as an antioxidant.. ${ }^{23}$ To generate superoxide anions, the reduction of $\mathrm{Ce}^{4+}$ to $\mathrm{Ce}^{3+}$ can produce damaging hydroxyl radicals. $\mathrm{Ce}^{3+}$ acts as an antioxidant when it reacts with hydroxyl radicals.10, 22, 24, 25
Thus, it has beenfound that the valence state of $\mathrm{Ce}$ decides whether CeO-NPs will play a protective or toxic role when exposed to cells. If the ratio of $3+/ 4+$ is higher, CeO-NPs will have increased toxicity and decreased antioxidant potential.

\section{In vitro and in vivo studies on nanoceria exposure}

Through multiple routes both normal and diseased states of mammalian cells was successfully up taken by CeO-NP. ${ }^{26} \mathrm{CeO}-\mathrm{NP}$ exhibits positive effects (such as scavenging ROS) and was used as a promising biomaterial for biomedical applications in most cases of in vitro intracellular assays, ${ }^{7}$ dephosphorylation of various substrates, aberrant cell signalling and alterations in the transcriptional and posttranslational levels, $\mathrm{CeO}-\mathrm{NP}$ could induce oxidative stress and DNA damage. 22,27,28 Through autophagy and a mitochondrial apoptosis pathway CeO-NP could induce cytotoxicity. ${ }^{27}$ The cytotoxicity of CeO-NP with cell types or particle size/preparations of simple correlations has not been established. ${ }^{29}$

Peroral, intravenous or intraperitoneal administrations of CeO-NPs to laboratory animals were used for studying the in vivo activity of these nanoparticles. The degeneration of retina induced by intracellular peroxides could be prevented by CeO-NP.30 Animal models for the diseases like ischemic stroke,,$^{31}$ lupus, ${ }^{32}$ diabetes, ${ }^{33}$ radiation-induced pneumonitis, ${ }^{34}$ and ischemic cardiomyopathy ${ }^{35}$ could be found to be prevented by CeO-NPs administration. The effect can be attributed due to the ROS scavenging ability of CeO-NPs. CeO-NP resulted in significant lung responses, including lung inflammation, lung injury, cytotoxicity, induction of phospholipidosis, alveolar macrophage functional changes, and release of pro-inflammatory and fibrotic cytokines when, exposed to animals. ${ }^{36} \mathrm{CeO}-\mathrm{NP}$ was shown to induce myocardial fibroblast proliferation, collagen deposition in rats related to fibrosis of the heart. ${ }^{37}$ Since cerium is not found in humans, systemic toxicity may be found as there is no clearance mechanism for this metal.

\section{Reactive oxygen species (ROS) and ROS scavenging mechanism}

Free radicals, such as superoxide $\left(\mathrm{O}_{2^{0^{-}}}\right)$, hydrogen peroxide $\left(\mathrm{H}_{2} \mathrm{O}_{2}\right)$, and peroxynitrite (ONOO-) are highly reactive metabolites of oxygen known as reactive oxygen species (ROS). The generation of ROS is depicted using band gap diagram is shown in Fig. 1.

In the intracellular and extracellular environment, antioxidants exists both in enzymatic and non-enzymatic forms. In different pathophysiological conditions ROS and RNS are responsible for the 


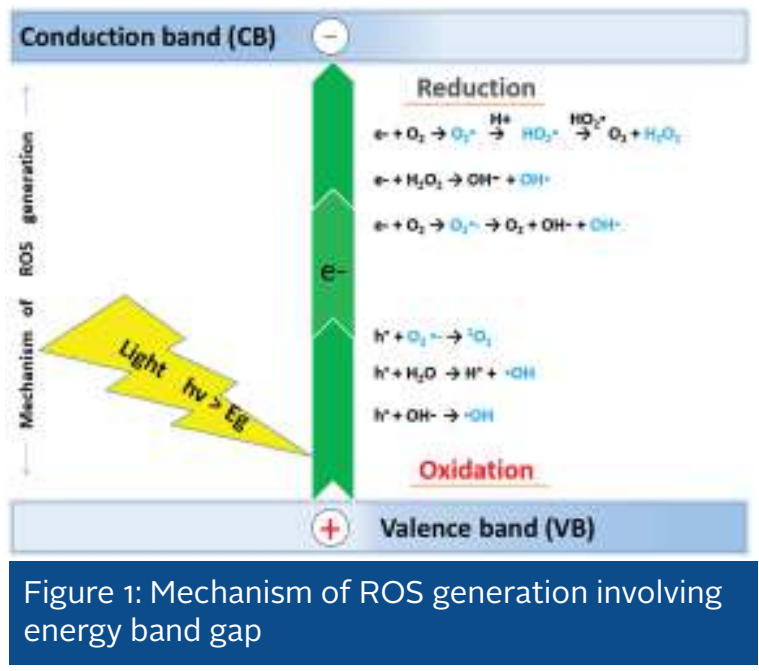

oxidative stress. ${ }^{38}$ By enhancing cellular defenses in the form of antioxidant, the oxidative stress can be effectively neutralized. 39,40 Superoxide dismutase (SOD), catalase (CAT), glutathione peroxidase (GSHPx) are protective enzymes that increases the level of endogenous antioxidants and scavenges free radicals. ${ }^{41}$ Based on their activity, antioxidants can be categorized as enzymatic and nonenzymatic antioxidants. Breakdown and removing the free radicals are executed by the enzymatic antioxidants. In a multi-step process, in the presence of cofactors such as zinc, copper, iron, and manganese, the antioxidant enzymes convert harmful oxidative products to hydrogen peroxide $\left(\mathrm{H}_{2} \mathrm{O}_{2}\right)$ and then to water. Interrupting the free radical chain reactions are executed by the non-enzymatic antioxidants. Carotenoids, vitamin C, plant polyphenol, vitamin E, and glutathione are the few examples of the non-enzymatic antioxidants. ${ }^{42}$ The inducers and scavengers of ROS are shown in Fig.2.

Inside the cells, there is a cellular imbalance between endogenous antioxidant defences (free radical scavenging by small molecule antioxidants and/or redox enzymes) and ROS generation (e.g., superoxide radical anion $\left(\mathrm{O}_{2} \bullet-\right)$; hydrogen peroxide $\left(\mathrm{H}_{2} \mathrm{O}_{2}\right)$; hydroxyl radical $(\bullet \mathrm{OH})$. This imbalance is one of its

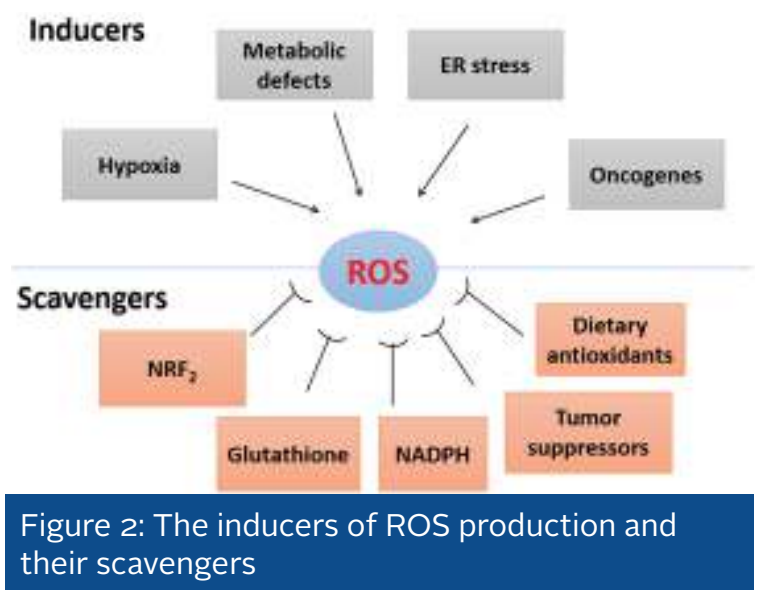

primary characteristics of oxidative stress which causes many serious diseases. As a result of normal cellular metabolism, the production of $\mathrm{O}_{2} \bullet-$ acts as a signalling molecule in the cellular environment. Activation of NADPH oxidases during inflammatory responses and/or disruption of the mitochondrial electron transport chain and interference with ATP production $\mathrm{O}_{2} \cdot-$ levels can rise quickly. Through the activity of superoxide dismutase (SOD) enzymes ${ }^{43}$ located extracellularly and in the cytoplasm and mitochondria, the toxic effects from excess $\mathrm{O}_{2} \bullet$-are normally controlled and reduced. By converting $\mathrm{O}_{2} \bullet-$ into $\mathrm{H}_{2} \mathrm{O}_{2}$ and $\mathrm{O}_{2}$ through a two-step, catalytic dismutation reaction and thus, SOD enzyme eradicates $\mathrm{O}_{2} \cdot-.44$

(1) $\mathrm{O}_{2} \cdot-+2 \mathrm{H}++(\mathrm{Cu}+)-\mathrm{SOD} \rightarrow \mathrm{H}_{2} \mathrm{O}_{2}+\left(\mathrm{Cu}^{2+}\right)-\mathrm{SOD}$

(2) $\mathrm{O}_{2} \cdot-+\left(\mathrm{Cu}^{2+}\right)-\mathrm{SOD} \rightarrow \mathrm{O}_{2}+\left(\mathrm{Cu}^{+}\right)-\mathrm{SOD}$

(3) $2 \mathrm{O}_{2} \cdot-+2 \mathrm{H}^{+} \rightarrow \mathrm{H}_{2} \mathrm{O}_{2}+\mathrm{O}_{2}$ (overall)

$\mathrm{H}_{2} \mathrm{O}_{2}$ is finally reduced to water by the enzyme catalase (CAT).

$$
\begin{gathered}
2 \mathrm{H}_{2} \mathrm{O}_{2} \rightarrow 2 \mathrm{H}_{2} \mathrm{O}+\mathrm{O}_{2} \\
\text { CAT }
\end{gathered}
$$

The removal or addition of electrons to $\mathrm{O}_{2} \cdot$-is done by SOD enzyme. The above reactions explain the scavenging effect by the antioxidant enzymes. In step (1), the removal of an electron from $\mathrm{O}_{2} \bullet-$ to generate $\mathrm{H}_{2} \mathrm{O}_{2}$ is followed by the reduction of $\left(\mathrm{Cu}^{+}\right)$-SOD. On the other hand in step (2), the addition of an electron to another molecule of $\mathrm{O}_{2} \cdot-$ to generate $\mathrm{O}_{2}$, is followed by the oxidation of $\left(\mathrm{Cu}^{2+}\right)$-SOD, (which is generated in step (1).To start the cycle again, reduction of $\left(\mathrm{Cu}^{+}\right)$-SOD is regenerated. To produce every molecule of $\mathrm{H}_{2} \mathrm{O}_{2}$, all two $\mathrm{O}_{2} \bullet-$ molecules are dismutated. Similarly, as reported above the presumed catalytic mechanism occurs through scavenging of $\mathrm{O}_{2} \bullet-$ by $\mathrm{CeO}-\mathrm{NPs}^{30}{ }^{30}$

$$
\begin{aligned}
& \text { (4) } \mathrm{O}_{2} \cdot-+\mathrm{Ce}^{3+}+2 \mathrm{H}^{+} \rightarrow \mathrm{H}_{2} \mathrm{O}_{2}+\mathrm{Ce}^{4+}\left(\mathrm{Ce}^{3+}\right. \text { is } \\
& \text { oxidized }) \\
& \text { (5) } \mathrm{O}_{2} \cdot-+\mathrm{Ce}^{4+} \rightarrow \mathrm{O}_{2}+\mathrm{Ce}^{3+}\left(\mathrm{Ce}^{4+} \text { is reduced }\right)
\end{aligned}
$$

The ROS generated in our body has dual effect based on the amount generated which is shown in Fig. 3.

In the actual biological environment these reactions are illustrated by the regenerative capacity of the $\mathrm{Ce}^{3+} / \mathrm{Ce}^{4+}$ redox couple, and it was previously not clear that these are the identical SOD-mimetic reactions that occur with $\mathrm{CeO}-\mathrm{NPs}$. The first investigators to demonstrate the SOD-mimetic activity of CeO-NPs were Korsvik et al. ${ }^{10}$. To be more efficient scavengers of $\mathrm{O}_{2} \bullet-$, $\mathrm{CeO}-\mathrm{NPs}$ were prepared with lower $\mathrm{Ce}^{3+} / \mathrm{Ce}^{4+}$ ratios on the surface and were compared with $\mathrm{CeO}-\mathrm{NPs}$ having a high $\mathrm{Ce}^{3+} / \mathrm{Ce}^{4+}$ ratio (higher levels of $\mathrm{Ce}^{3+}$ on the surface). The study revealed that CeO-NPs with low $\mathrm{Ce}^{3+} / \mathrm{Ce}^{4+}$ surface ratios (higher proportion of surface $\mathrm{Ce}^{4+}$ 


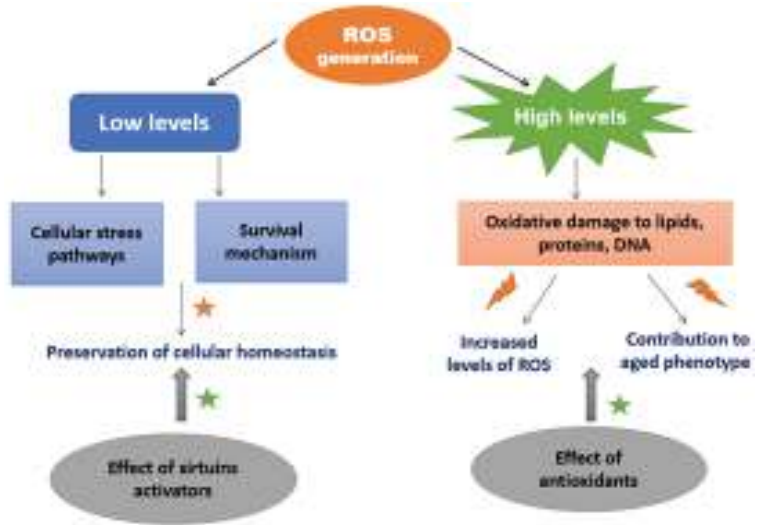

Dual roles of Reactive Oxygen Species - ROS levels

Figure 3: The dual role of ROS level in our body

ions) were not effective SOD-mimetics as compared to the CeO-NPs having a higher $\mathrm{Ce}^{3+} / \mathrm{Ce}^{4+}$ surface ratio. 45

\section{Antioxidant ROS/RNS scavenging activity of ceria nanoparticles}

The effective reduction in $\mathrm{O}_{2} \bullet-$ and $\mathrm{H}_{2} \mathrm{O}_{2}$ levels using CeO-NPs have been demonstrated through their antioxidant SOD- and CAT-mimetic activity. The CeO-NPs have been however, found to be efficient scavengers for other ROS such as $\mathrm{OH} \bullet 25,46-48$ and also for RNS such as nitric oxide radical (NO•) 49, 50 and peroxynitrite $\left(\mathrm{O}_{2} \mathrm{NO}^{-}\right) .^{51} \mathrm{CeO}-\mathrm{NPs}$ possess innate $\mathrm{OH}$. scavenging potential from $\mathrm{H}_{2} \mathrm{O}_{2}$ which was also indirectly suggested. ${ }^{25}$ Further, Xue et al., showed that CeO-NPs can efficiently scavenge $\mathrm{OH}$ • based on NP size and $\mathrm{Ce}^{3+}$ surface levels. CeO-NPs can prevent the reduction of absorbance of the dye methyl violet with efficient $\mathrm{OH}$ • scavenging. The scavenging was efficient and as size of the CeO-NPs decreased and as the level of $\mathrm{Ce}^{3+}$ on the surface of the NPs increased (higher $\mathrm{Ce}^{3+} / \mathrm{Ce}^{4+}$ surface ratios). Switch from $\mathrm{Ce}^{3+}$ to $\mathrm{Ce}^{4+}$ is a key factor for their ROS scavenging activity and it was the reversible ability of CeO-NPs. There are two step mechanism for the $\mathrm{OH}$ - scavenging activity of CeO-NPs, where the oxidation of $\mathrm{Ce}^{3+}$ by $\mathrm{OH}$ • indicates the first step and the reduction of $\mathrm{Ce}^{4+}$ to regenerate $\mathrm{Ce}^{3+}$ indicates the second step. 47

(7) $\mathrm{Ce}_{2} \mathrm{O}_{2}+2[\cdot \mathrm{OH}] \rightarrow 2 \mathrm{CeO}_{2}+\mathrm{H}_{2} \mathrm{O}$

(8) $2 \mathrm{CeO}_{2}$ (in presence of aqueous $\left.\mathrm{H}^{+}\right) \rightarrow \mathrm{Ce}_{2} \mathrm{O}_{3}$ $+1 / 2 \mathrm{O}_{2}$

\section{Discussion and Conclusion}

Reactive oxygen species (ROS) are highly reactive metabolites of oxygen, such as superoxide $\left(\mathrm{O}_{2} \cdot-\right)$, hydrogen peroxide $\left(\mathrm{H}_{2} \mathrm{O}_{2}\right)$, and peroxynitrite (ONOO-). Their lifetime in biological systems ranges from nanoseconds to seconds depending on their reactivity and the level of cellular antioxidants.
ROS can exist in both +3 and +4 oxidation state. Although the effect of chronic low dose exposure to oxidant in mammalian cells changes its sensitivity to higher doses of oxidants. ${ }^{52,53}$ Nanoceria or cerium oxide nanostructure (cluster, particles etc.) are metal oxide semiconductors that have profound applications due to their unique characteristics like high chemical and thermal stability, oxygen storage capability, redox nature and other physicochemical properties which are size tunable.54-57 The nanoceria has a face centered cubic fluorite structure with Fm3m crystal structure. In this structure the $\mathrm{Ce}^{4+}$ cations are placed in the corner of the cubes that are coordinated to the O2- ions which are present in the tetrahedral voids. ${ }^{58}$ Apart from $\mathrm{Ce}^{+4}$, the ions of cerium can also exist in $\mathrm{Ce}^{+3}$ state in the crystal phase of nanoceria and the interconversion energy is very low between these two oxidation states ${ }^{59}$ which enables the formation of oxygen vacancies inside the crystal. This unique redox property makes nanoceria suitable for various applications like catalyst in automobile exhaust, an agent with antioxidant applications, solid oxide fuel cells (SOFC), as a sensor for detecting oxygen gas, in membrane systems for oxygen permeability, used as a catalyst for chemical reactions which involves oxidation. ${ }^{60-63}$ The ratio of $\mathrm{Ce}^{3+}$ to $\mathrm{Ce}^{4+}$ present in the crystal of nanoceria plays the most important role in exhibiting its redox properties. According to literature, the size and surface morphology of the nanostructures of ceria is responsible for the $\mathrm{Ce}^{3+}$ amount present in the facets of crystal.58, 64 If the overall dimension of the nanoceria crystal reduces there are more favorable chances of high $\mathrm{Ce}^{3+}$ to $\mathrm{Ce}^{4+}$ ratio due to high surface to volume ratio. ${ }^{65}$ When the oxidation state of nanoceria reduces from $\mathrm{Ce}^{4+}$ to $\mathrm{Ce}^{3+}$, it is speculated that there is generation of superoxide anions, thus contributing for the generation of harmful hydroxyl radical and acts as a prooxidant. Another postulation concludes that $\mathrm{Ce}^{3+}$ can react with the hydroxyl radicals and contributes for the antioxidant properties. $^{10,17,22,25}$ Thus, we can state that the valance state of cerium can play a vital role in deciding whether CeO-NPs will exert a protective property or a toxic role when exposed to a biological system. ${ }^{66}$ The dual valance state has also been utilized to design ceria nanocluster based ROS sensor. ${ }^{67}$ We can conclude from the previous research that the valence state of $\mathrm{CeO}-\mathrm{NPs}$ can decide whether they are prooxidant or antioxidant and when the ratio of $\mathrm{Ce}^{3+} / \mathrm{Ce}^{4+}$ increases the toxicity gets enhanced thereby decreasing its antioxidant potential. This shows the dual role of nanoceria as an antioxidant as well as prooxidant depending on size, surface morphology and the ratio of $\mathrm{Ce}^{3+} / \mathrm{Ce}^{4+}$ on the surface of the crystal. 


\section{Acknowledgement}

We are grateful to Chettinad Academy of Research and Education for providing us with infrastructural support to prepare this manuscript.

\section{Conflict of Interest}

The authors declare no conflict of interest.

\section{References}

1. Noguera C. Physics and chemistry at oxide surfaces: Cambridge University Press; 1996.

2. Kung $\mathrm{HH}$. Transition metal oxides: surface chemistry and catalysis: Elsevier; 1989.

3. Henrich V, Cox P. The Surface Science of Metal Oxides Cambridge Univ. Press Cambridge; 1994.

4. Girigoswami K, Viswanathan M, Murugesan R, Girigoswami A. Studies on polymer-coated zinc oxide nanoparticles: UV-blocking efficacy and in vivo toxicity. Materials Science and Engineering: C. 2015;56:501-10.

5. Rodríguez JA, Fernández-García M. Synthesis, properties, and applications of oxide nanomaterials: John Wiley \& Sons; 2007.

6. Fernández-García M, Wang X, Belver C, Hanson JC, Rodriguez JA. Anatase-TiO2 nanomaterials: Morphological/size dependence of the crystallization and phase behavior phenomena. The Journal of Physical Chemistry C. 2007;111(2):674-82.

7. Karakoti AS, Tsigkou O, Yue S, Lee PD, Stevens MM, Jones JR, et al. Rare earth oxides as nanoadditives in 3-D nanocomposite scaffolds for bone regeneration. Journal of Materials Chemistry. 2010;20(40):8912-9.

8. Inoue M, Kimura M, Inui T. Transparent colloidal solution of $2 \mathrm{~nm}$ ceria particles. Chemical Communications. 1999(11):957-8.

9. Dahle JT, Arai Y. Environmental geochemistry of cerium: applications and toxicology of cerium oxide nanoparticles. International journal of environmental research and public health. 2015;12(2):1253-78.

10. Korsvik C, Patil S, Seal S, Self WT. Superoxide dismutase mimetic properties exhibited by vacancy engineered ceria nanoparticles. Chemical communications. 2007(10):1056-8.

11. Jakupec $M$, Unfried $P$, Keppler $B$. Pharmacological properties of cerium compunds. Reviews of physiology, biochemistry and pharmacology: Springer; 2005. p. 101-11.

12. Ji Y, Xiao B, Wang Z, Cui M, Lu Y. The suppression effect of light rare earth elements on proliferation of two cancer cell lines. Biomedical and environmental sciences: BES. 2000;13(4):287-92.
13. Trovarelli A. Catalytic properties of ceria and CeO2-containing materials. Catalysis Reviews. 1996;38(4):439-520.

14. Skorodumova N, Simak S, Lundqvist BI, Abrikosov I, Johansson B. Quantum origin of the oxygen storage capability of ceria. Physical Review Letters. 2002;89(16):166601.

15. Deshpande S, Patil S, Kuchibhatla SV, Seal S. Size dependency variation in lattice parameter and valency states in nanocrystalline cerium oxide. Applied Physics Letters. 2005;87(13):133113.

16. Mandoli C, Pagliari F, Pagliari S, Forte G, Di Nardo $P$, Licoccia $S$, et al. Stem cell aligned growth induced by $\mathrm{CeO}_{2}$ nanoparticles in PLGA scaffolds with improved bioactivity for regenerative medicine. Advanced Functional Materials. 2010;20(10):1617-24.

17. Celardo I, Pedersen JZ, Traversa E, Ghibelli L. Pharmacological potential of cerium oxide nanoparticles. Nanoscale. 2011;3(4):1411-20.

18. Reed K, Cormack A, Kulkarni A, Mayton M, Sayle D, Klaessig F, et al. Exploring the properties and applications of nanoceria: is there still plenty of room at the bottom? Environmental Science: Nano. 2014;1(5):390-405.

19. Tsunekawa S, Sivamohan R, Ito S, Kasuya A, Fukuda T. Structural study on monosize $\mathrm{CeO}_{2}-\mathrm{x}$ nano-particles. Nanostructured materials. 1999;11(1):141-7.

20. Tsunekawa S, Sivamohan R, Ohsuna T, Takahashi $\mathrm{H}$, Tohji $\mathrm{K}$, editors. Ultraviolet absorption spectra of $\mathrm{CeO} 2$ nano-particles. Materials Science Forum; 1999: Trans Tech Publ.

21. Lin W, Huang Y-W, Zhou X-D, Ma Y. Toxicity of cerium oxide nanoparticles in human lung cancer cells. International journal of toxicology. 2006;25(6):451-7.

22. Park E-J, Choi J, Park Y-K, Park K. Oxidative stress induced by cerium oxide nanoparticles in cultured BEAS-2B cells. Toxicology. 2008;245(1-2):90-100.

23. Eom H-J, Choi J. Oxidative stress of $\mathrm{CeO}_{2}$ nanoparticles via p38-Nrf-2 signaling pathway in human bronchial epithelial cell, Beas-2B. Toxicology letters. 2009;187(2):77-83.

24. Celardo I, De Nicola M, Mandoli C, Pedersen JZ, Traversa E, Ghibelli L. Ce3+ ions determine redox-dependent anti-apoptotic effect of cerium oxide nanoparticles. ACS nano. 2011;5(6):4537-49.

25. Das M, Patil S, Bhargava N, Kang J-F, Riedel LM, Seal S, et al. Auto-catalytic ceria nanoparticles offer neuroprotection to adult rat spinal cord neurons. Biomaterials. 2007;28(10):1918-25.

26. Wason MS, Zhao J. Cerium oxide nanoparticles: potential applications for cancer and other 
diseases. American journal of translational research. 2013;5(2):126.

27. Hussain S, Al-Nsour F, Rice AB, Marshburn J, Yingling $B$, Ji $Z$, et al. Cerium dioxide nanoparticles induce apoptosis and autophagy in human peripheral blood monocytes. ACS nano. 2012;6(7):5820-9.

28. Cheng G, Guo W, Han L, Chen E, Kong L, Wang L, et al. Cerium oxide nanoparticles induce cytotoxicity in human hepatoma SMMC-7721 cells via oxidative stress and the activation of MAPK signaling pathways. Toxicology in Vitro. 2013;27(3):1082-8.

29. Asati A, Santra S, Kaittanis C, Perez JM. Surface-charge-dependent cell localization and cytotoxicity of cerium oxide nanoparticles. ACS nano. 2010;4(9):5321-31.

30. Chen J, Patil S, Seal S, McGinnis JF. Rare earth nanoparticles prevent retinal degeneration induced by intracellular peroxides. Nature nanotechnology. 2006;1(2):142.

31. Kim CK, Kim T, Choi IY, Soh M, Kim D, Kim YJ, et al. Ceria nanoparticles that can protect against ischemic stroke. Angewandte Chemie International Edition. 2012;51(44):11039-43.

32. Rzigalinski BA, Meehan K, Davis RM, Xu Y, Miles WC, Cohen CA. Radical nanomedicine. 2006.

33. Pourkhalili N, Hosseini A, Nili-Ahmadabadi A, Hassani S, Pakzad M, Baeeri M, et al. Biochemical and cellular evidence of the benefit of $a$ combination of cerium oxide nanoparticles and selenium to diabetic rats. World journal of diabetes. 2011;2(11):204.

34. Colon J, Herrera L, Smith J, Patil S, Komanski C, Kupelian $P$, et al. Protection from radiation-induced pneumonitis using cerium oxide nanoparticles. Nanomedicine: Nanotechnology, Biology and Medicine. 2009;5(2):225-31.

35. Niu J, Azfer A, Rogers LM, Wang X, Kolattukudy PE. Cardioprotective effects of cerium oxide nanoparticles in a transgenic murine model of cardiomyopathy. Cardiovascular research. 2007;73(3):549-59.

36. Ma JY, Zhao H, Mercer RR, Barger M, Rao M, Meighan $T$, et al. Cerium oxide nanoparticle-induced pulmonary inflammation and alveolar macrophage functional change in rats. Nanotoxicology. 2011;5(3):312-25.

37. Srinivas A, Rao PJ, Selvam G, Murthy PB, Reddy PN. Acute inhalation toxicity of cerium oxide nanoparticles in rats. Toxicology Letters. 2011;205(2):105-15.

38. Kim Y-W, Byzova TV. Oxidative stress in angiogenesis and vascular disease. Blood, The Journal of the American Society of Hematology. 2014;123(5):625-31.
39. Sies H. Oxidative stress: oxidants and antioxidants. Experimental Physiology: Translation and Integration. 1997;82(2):291-5.

40. Pal D, Nimse S. Screening of the antioxidant activity of Hydrilla verticillata plant. Asian Journal of Chemistry. 2006;18(4):3004.

41. Nimse SB, Pal D. Free radicals, natural antioxidants, and their reaction mechanisms. Rsc Advances. 2015;5(35):27986-8006.

42. Shahidi F, Zhong Y. Novel antioxidants in food quality preservation and health promotion. European Journal of Lipid Science and Technology. 2010;112(9):930-40.

43. McCord JM, Fridovich I. Superoxide dismutase an enzymic function for erythrocuprein (hemocuprein). Journal of Biological chemistry. 1969;244(22):6049-55.

44. Ivanov VK, Shcherbakov AB, Usatenko A Structure-sensitive properties and biomedical applications of nanodispersed cerium dioxide. Russian chemical reviews. 2009;78(9):855.

45. Heckert EG, Karakoti AS, Seal S, Self WT. The role of cerium redox state in the SOD mimetic activity of nanoceria. Biomaterials. 2008;29(18):2705-9.

46. Xue Y, Zhai Y, Zhou K, Wang L, Tan H, Luan Q, et al. The vital role of buffer anions in the antioxidant activity of $\mathrm{CeO}_{2}$ nanoparticles. Chemistry-A European Journal. 2012;18(35):11115-22.

47. Xue Y, Luan Q, Yang D, Yao X, Zhou K. Direct evidence for hydroxyl radical scavenging activity of cerium oxide nanoparticles. The Journal of Physical Chemistry C. 2011;115(11):4433-8.

48. Zhang Y, Zhou K, Zhai Y, Qin F, Pan L, Yao X. Crystal plane effects of nano- $\mathrm{CeO}_{2}$ on its antioxidant activity. 2014.

49. Dowding JM, Das S, Kumar A, Dosani T, McCormack R, Gupta A, et al. Cellular interaction and toxicity depend on physicochemical properties and surface modification of redox-active nanomaterials. ACS nano. 2013;7(6):4855-68.

50. Dowding JM, Dosani T, Kumar A, Seal S, Self WT. Cerium oxide nanoparticles scavenge nitric oxide radical ( NO). Chemical communications. 2012;48(40):4896-8.

51. Dowding JM, Seal S, Self WT. Cerium oxide nanoparticles accelerate the decay of peroxynitrite (ONOO-). Drug delivery and translational research. 2013;3(4):375-9.

52. Girigoswami KB, Bhaumik G, Ghoshl R. Chronic low dose exposure to hydrogen peroxide changes sensitivity of V79 cells to different damaging agents. Indian journal of experimental biology. 2003;41:832-6. 
53. Ghosh R, Girigoswami K, Guha D. Suppression of apoptosis leads to cisplatin resistance in V79 cells subjected to chronic oxidative stress. 2012.

54. Ahniyaz A, Sakamoto Y. Tuning the aspect ratio of ceria nanorods and nanodumbbells by a face-specific growth and dissolution process. Crystal Growth and Design. 2008;8(6):1798-800.

55. Trovarelli A, de Leitenburg C, Boaro M, Dolcetti G. The utilization of ceria in industrial catalysis. Catalysis today. 1999;50(2):353-67.

56. Yamashita M, Kameyama K, Yabe S, Yoshida S, Fujishiro Y, Kawai T, et al. Synthesis and microstructure of calcia doped ceria as UV filters. Journal of materials science. 2002;37(4):683-7.

57. Imagawa H, Suda A, Yamamura K, Sun S. Monodisperse $\mathrm{CeO}_{2}$ nanoparticles and their oxygen storage and release properties. The Journal of Physical Chemistry C. 2011;115(5):1740-5.

58. Sun C, Li H, Chen L. Nanostructured ceria-based materials: synthesis, properties, and applications. Energy \& Environmental Science. 2012;5(9):8475-505.

59. Garcia T, Solsona B, Taylor SH. Nano-crystalline ceria catalysts for the abatement of polycyclic aromatic hydrocarbons. Catalysis Letters. 2005;105(3-4):183-9.

6o. Maensiri S, Masingboon C, Laokul P, Jareonboon W, Promarak V, Anderson PL, et al. Egg white synthesis and photoluminescence of platelike clusters of $\mathrm{CeO} 2$ nanoparticles. Crystal growth \& design. 2007;7(5):950-5.
61. Palmisano P, Russo N, Fino P, Fino D, Badini C. High catalytic activity of SCS-synthesized ceria towards diesel soot combustion. Applied Catalysis B: Environmental. 2006;69(1-2):85-92.

62. Bellino MG, Lamas DG, Walsöe de Reca N. Enhanced ionic conductivity in nanostructured, heavily doped ceria ceramics. Advanced Functional Materials. 2006;16(1):107-13.

63. Mai H-X, Sun L-D, Zhang Y-W, Si R, Feng W, Zhang $\mathrm{H}-\mathrm{P}$, et al. Shape-selective synthesis and oxygen storage behavior of ceria nanopolyhedra nanorods, and nanocubes. The Journal of Physical Chemistry B. 2005;109(51):24380-5.

64. Krishnan A, Sreeremya TS, Ghosh S. Size-tunable hydrophilic cerium oxide nanoparticles as a 'turn-on'fluorescence sensor for the rapid detection of ultralow concentrations of vitamin C. RSC advances. 2016;6(58):53550-9.

65. Dunnick KM, Pillai R, Pisane KL, Stefaniak AB, Sabolsky EM, Leonard SS. The effect of cerium oxide nanoparticle valence state on reactive oxygen species and toxicity. Biological trace element research. 2015;166(1):96-107.

66. Thendral V, Dharshni T, Ramalakshmi $M$, Girigoswami A, Girigoswami K. Cerium oxide nanocluster based nanobiosensor for ROS detection. Biocatalysis and agricultural biotechnology. 2019;19:101124. 